\title{
Empirical Association between Education and Happiness in a Social Context
}

\author{
Gezim Zeqiri ${ }^{1}$ \\ 1 Syracuse University \\ 900 South Crouse Ave, Syracuse, New York, 13244, USA
}

DOl: $10.22178 /$ pos.61-4

LCC Subject Category:

LB2300-2430

Received 14.07.2020

Accepted 28.08.2020

Published online 31.08.2020

Corresponding Author:

gzeqiri@syr.edu

Abstract. Education level and the number of school years completed have an important function in each persons' life and are considered as one of the most important aspects of socialization, fulfillment, income level, and general happiness. In particular, the number of school years completed is an important indicator which we intend to utilize to estimate educations' impact on one's life in general. Differently put, among many other aspects of educations' impact on humans' life, this article focuses on the relation between the highest numbers of school year completed and the general happiness of a person.

The purpose of the article is to find evidence that proves that the general happiness and the highest school year completed are not statistically independent. Finding the correlation between these two variables is the objective of the article. For that purpose, we analyzed the empirical data provided by the General Social Survey (GSS) by conducting a chi-square statistics test to prove the existence of a relationship between the variables.

(c) 2020 The Author. This

article is licensed under a

Creative Commons

Attribution 4.0 License

(a) (1)

Put another way, the research intends to analyze data provided by GSS2008.dta and test the null and alternative hypothesis by using the chi-square statistics test and by applying the quantitative methodology of research. The data collected from 2,018 respondents provided by GSS are analyzed by utilizing State Software - as one of the most reliable and contemporary tools used by scientists nowadays.

Keywords: education; happiness; relation; association.

\section{INTRODUCTION}

Does the number of school years completed impact peoples' level of happiness? Are happiness and education-related? Is it worth it to expand energy and efforts to achieve the highest levels of education? Will this impact our level of happiness?

To answer the above-mentioned questions, we will conduct research and analyze whether there is a relation between the accomplished years of education and the happiness level of people in the United States. In that context, the main research question of this article is as follows: Is there a relationship between education level achieved and general happiness?

This will be done by relating the variable "general level of happiness", and by analyzing its' relation to the number of school years completed. Further, since the increased education level is expected to raise the level of income, we will examine the relationship between education and income as well. In this particular context, the purpose of this examination is to see whether an increased level of income caused by a higher level of education is significant to the general happiness.

Simply put, our articles' objective is to assess the extent to which there is a relationship between education and happiness level among US adults.

Overall, the article will be focused on the impact of the level of education on the overall happiness of a person. Based on the statistical output of the General Social Survey (GSS) variables, we will be able to see whether the increased level of education effects happiness.

Based on these results, we will be able to find an answer to the article's research question and find indicators of there a relationship between the number of school years completed and the general happiness level?

Finally, we expect that the findings of the article will also confirm/accept our alternative hypothesis which claims that there is a relationship between education and happiness. In other words, 
our alternative hypothesis declaration is as follows: there is an association between the level of education and general happiness. The article aims to contradict the null hypothesis which suggests there is no such relation.

\section{METHODS}

The data used in this article to relate education with happiness will be extracted from the General Social Survey (GSS). "The GSS is a publicly available national resource, widely used by sociologists, analysts, students, economists, health care providers, and many others. GSS data are used in numerous news articles, magazine, and journal articles, by legislators, policymakers, and educators" [2]. Thus, to conduct quantitative research, we used the GSS data. Having said that, we can declare that this article is based on appropriate and reliable data.

We have analyzed two main variables used from GSS data: general happiness and the highest number of school years completed. In the beginning, we collected and examined data related to demographics - including gender, age, level of education, and financial situation. Then we analyzed in-depth the relationship between the variable of education and the general happiness of the people of the United States. We wanted to see at what extend are the general happiness and education level related.

The total number of people who responded to the survey about their highest school year completed was 2,018 respondents. Among all these respondents, there is a variety of levels and types of education. Considering the variety of university diplomas issued in the US or abroad, and having in mind there might be also different kinds of educational systems around the world, we assumed US citizens might have received many kinds of educational services. In that context, to include any type of education received, we categorized data into two categories that represent the number of school years completed despite the educational system. We assumed that in general people go to college after approximately 12 school years. Based on that, we compiled the data into a new variable "school-college" which contains two categories: 1 year to 12 school years; 12 to 20 school years.

These categories are utilized to compare the level of education to the level of peoples' happiness.
Respondents who have completed more school years than others, or have obtained higher degrees, may have increased their probability to be more competitive, to have a better job, to increase their income, and so forth. "According to US census data for the year 1998, the median earnings of the adult, year-round workers with professional degrees are about four times higher than those of adults who had not completed high school" [5]. Further, Table 1-4 provides us with GSS data which supports the idea of a positive relationship between the number of school years completed and the financial situation of the respondents.

Table 1 - General happiness and School-College: observed and expected frequencies

\begin{tabular}{|l|c|c|c|c|}
\hline \multirow{2}{*}{$\begin{array}{l}\text { School- } \\
\text { College }\end{array}$} & \multicolumn{4}{|c|}{ General Happiness } \\
\cline { 2 - 5 } & $\begin{array}{c}\text { Very } \\
\text { Happy }\end{array}$ & $\begin{array}{c}\text { Pretty } \\
\text { Happy }\end{array}$ & $\begin{array}{c}\text { Not too } \\
\text { happy }\end{array}$ & Total: \\
\hline School & 240 & 484 & 194 & 918 \\
& 272.2 & 501.5 & 144.3 & \\
\hline College & 356 & 614 & 122 & 1092 \\
& 323.8 & 596.5 & 171.7 & \\
\hline Total: & 596 & 1098 & 316 & 2010 \\
\hline Chi-square $=$ & 39.6080 & \multicolumn{5}{|c|}{ p-value $<0.001$} \\
\hline
\end{tabular}

Table 2 - Change in financial situation by School-College variable

\begin{tabular}{|l|l|l|l|l|l|}
\hline School-College & Better & Worse & $\begin{array}{l}\text { The } \\
\text { same }\end{array}$ & NA & Total \\
\hline $\begin{array}{l}\text { 0-12 school } \\
\text { years completed }\end{array}$ & 216 & 332 & 371 & 2 & 921 \\
\hline $\begin{array}{l}12-20 \text { school } \\
\text { years completed }\end{array}$ & 400 & 270 & 420 & 7 & 1097 \\
\hline NA & 2 & 1 & 1 & 1 & 5 \\
\hline Total: & 618 & 603 & 792 & 10 & 2023 \\
\hline
\end{tabular}

Table 3 - Highest year of school completed - recoded to "School-College"

\begin{tabular}{|l|l|l|}
\hline $\begin{array}{l}\text { School - College Highest } \\
\text { year of school completed }\end{array}$ & Frequency & Percent \\
\hline 1 & 921 & 45.53 \\
\hline 2 & 1,097 & 54.23 \\
\hline NA & 5 & 0.25 \\
\hline Total: & 2,023 & 100.00 \\
\hline
\end{tabular}

Table 4 - The variable "Highest number of school years completed"

\begin{tabular}{|c|c|c|}
\hline $\begin{array}{c}\text { Highest Year of School } \\
\text { Completed }\end{array}$ & Frequency & Percent \\
\hline 0 & 6 & 0.30 \\
\hline 2 & 2 & 0.10 \\
\hline
\end{tabular}




\begin{tabular}{|c|c|c|}
\hline $\begin{array}{c}\text { Highest Year of School } \\
\text { Completed }\end{array}$ & Frequency & Percent \\
\hline 3 & 5 & 0.25 \\
\hline 4 & 10 & 0.49 \\
\hline 5 & 5 & 0.25 \\
\hline 6 & 29 & 1.43 \\
\hline 7 & 14 & 0.69 \\
\hline 8 & 35 & 1.73 \\
\hline 9 & 53 & 2.62 \\
\hline 10 & 59 & 2.92 \\
\hline 11 & 122 & 6.03 \\
\hline 12 & 581 & 28.72 \\
\hline 13 & 158 & 7.81 \\
\hline 14 & 258 & 12.75 \\
\hline 15 & 94 & 4.65 \\
\hline
\end{tabular}

\begin{tabular}{|c|c|c|}
\hline $\begin{array}{c}\text { Highest Year of School } \\
\text { Completed }\end{array}$ & Frequency & Percent \\
\hline 16 & 322 & 15.92 \\
\hline 17 & 51 & 2.52 \\
\hline 18 & 124 & 6.13 \\
\hline 19 & 38 & 1.88 \\
\hline 20 & 52 & 2.57 \\
\hline NA & 5 & 0.25 \\
\hline Total: & 2,023 & 100.00 \\
\hline
\end{tabular}

Below we can see a graph representing the data in Figure 1.

12 - 20 school years completed

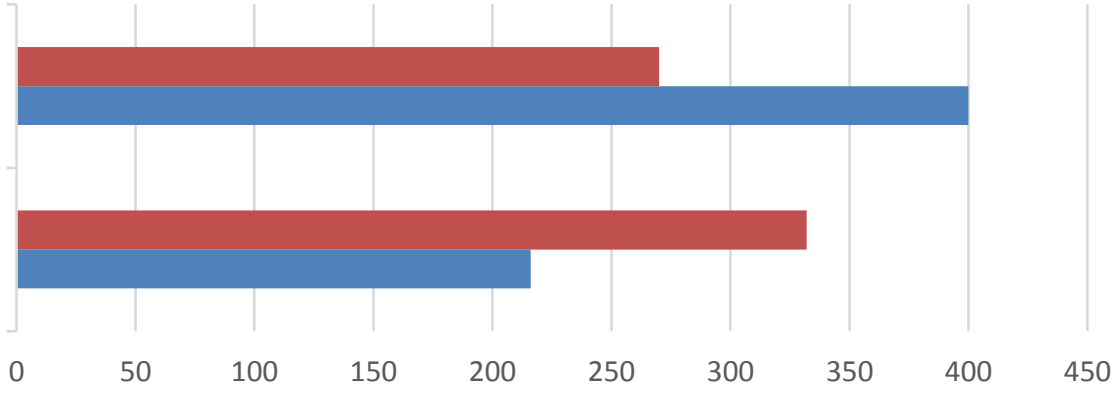

\begin{tabular}{|c|c|c|}
\hline & $0-12$ school years completed & $12-20$ school years completed \\
\hline Worse & 332 & 270 \\
\hline Better & 216 & 400 \\
\hline
\end{tabular}

Figure 1 - Change in a financial situation by School - College variable (Source: General Social Survey)

As we can notice in Figure 1, the financial situation of 400 respondents got better with 12-20 school years completed. This is much higher compared to 216 respondents' financial situation improved by having up to 12 years of school completed.

During the whole article, we have used a variety of tools and methods. Except for GSS, different other sources of information were used, including other research articles, scientific books, journals, and so on.

The data collected from GSS was elaborated by using contemporary and widely used software "STATA". The output of data evaluated in Stata is shown by tables and graphs on appendixes at the end of this article.

\section{LITERATURE REVIEW}

In general, achieving a higher level of happiness is the goal of most of the people. Thus, many authors' have tried to investigate this issue and find better ways of achieving happiness. In that context, Guignon and Russell have admitted that "philosophers and psychologists have long been concerned with the good life and how it can be achieved" [8]. However, "the science of happiness had not paid much attention to the effect of educational attainment on happiness (understood as life satisfaction)" [7].

"People want to be happy and, since this desire is well-nigh universal, we would expect to find happiness included as an aim of education" [6]. In that context, some authors tried to investigate this issue and find a connection, in some cases indirect relation, between happiness and education. Author [6] ran a multiple regression on an international sample to study the determinants of happiness and also found that educational attainment was not associated with life satisfaction. However, he went further and noted that education does affect life satisfaction indirectly through income, health, perceived trust, and social participation [7]. 
On the other hand, based on some other publications, education is thought to be an important factor influencing the life of a person. According to some authors, education has a significant role in many aspects of life, including general life satisfaction and happiness.

Authors [7] provided "evidence of the positive and significant effect of education on happiness". Moreover, "education is the strongest systematic determinant of individual participation in a variety of social activities, and social connections have been linked to increased health and well-being" [9].

In other words, the level of education is seen by many authors as an important factor influencing the life satisfaction and overall happiness of a person. However, the relationship between education and general happiness is not always on the same line. Author [10] suggests that the most educated people within societies will only be happier as long as their education yields them a clear status advantage. As these differentials erode in the most developed societies, higher education will be related negatively with happiness" [10]. In that context, a negative relationship between education level and happiness is provided by [10] who find a nonmonotonic relationship between education and happiness in the Netherlands" [10].

However, the direction of the relationship between education level and general happiness is not the subject of this study, while its purpose is to find empirical evidence of the existence of that relation.

\section{RESULTS AND DISCUSSION}

Based on the data collected on GSS, we came to some interesting results. As a start to the data analysis, we summarized some of the components of demographics. The total number of respondents based on the variable of "highest school year completed" is 2,018 people. Among them, there is a range of 20 school years completed, starting from zero to twenty. The highest frequency of respondents is 581 which corresponds to 12 school years completed. The lowest frequency is 2 people who completed only two years of school.

Based on the sample, there is a general mean of 13.43 school years completed, with a standard deviation of 3.07. Further, we wanted to look at the data to find any possible difference of education based on gender, and we found out that there is a slight difference in favor of male respondents who have a mean of 13.45 school years (3.12 sd), whereas female respondents have a mean of 13.41 years of education ( $3.04 \mathrm{sd})$.

To make it more convenient to analyze the data, we recorded the number of school years completed into new categories. The first category includes the first 12 school years completed, and it is supposed to represent the $\mathrm{K}$ to 12 school years. The second category represents the number of school years starting from 13 to 20, representing respondents who completed school years in college or university. Since the data provided offer us the number 20 as a given maximal number of school years completed, we limited this category to 20 years.

Based on the recoded data, we noticed that from the total number $(2,023)$ of respondents $45.53 \%$ of them fall into the first category. This means that approximately 921 respondents did not attend university-level studies. On the other hand, 1,097 respondents declared they completed more than 12 school years. This means that about $54.23 \%$ of respondents have attended university-level studies. The other $0.25 \%$ of respondents did not answer the question.

On the other hand, the other most important variable in this article gives us the data for the happiness of respondents, grouping them into three categories: very happy; pretty happy; not too happy.

To find whether there is a relationship between the highest numbers of school year completed, we conducted a Chi-square test. This is a widely used method to test the hypothesis and as a way to measure whether we can reject the null hypothesis and prove that the association between different variables exist. Chi-square's test output gives information about the actual observed frequencies values and the expected frequencies. This way, we can find the difference between them and determine whether that difference is significant or not.

By comparing the variable of "general happiness" with the recoded variable "school-college", we came to some interesting results. Using Stata software, we found out that the coefficient of Chisquare between those variables is $X^{2}=39.6080$.

To find out whether this coefficient is significant or not, we calculated the Degree of Freedom and found the Critical Value at the alpha level of $95 \%$ confidence (Alpha=0.05). 
$\mathrm{df}=(\mathrm{r}-1)(\mathrm{c}-1)=(2-1)(3-1)=1 \times 2=2$.

Based on the alpha level and the degrees of freedom, we could find the Critical Value $=5.99$ (table 5 below).

\section{Table 5}

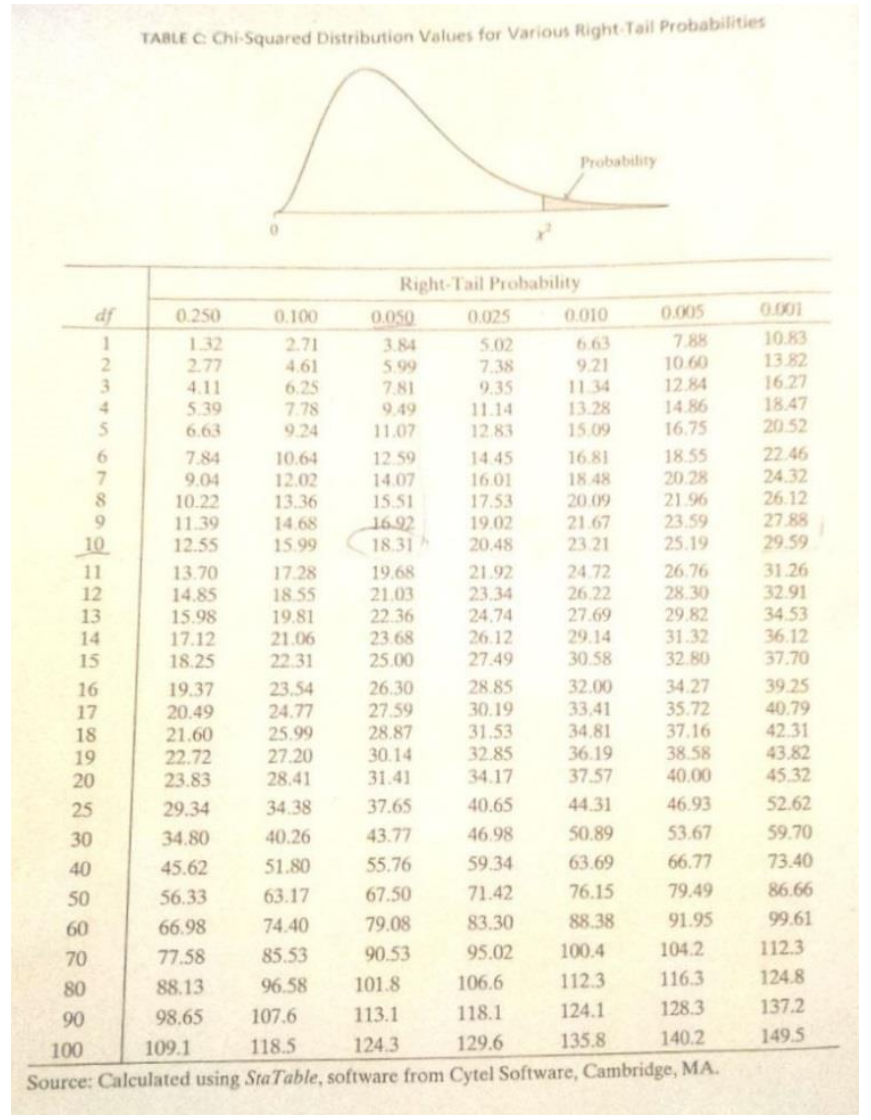

At the same table, we found the p-value was smaller than 0.001 .

Even if we analyze the variable "Educ" (before recording it), and compare it to the general happiness level, at $\alpha=0.05$ we would find these results: $X^{2}=107.2253 ; \mathrm{df}=38$; Critical Value $=53.384$; $\mathrm{p}$ value $<0.001$.

While analyzing the results below, we will see that in both cases, the conclusion concerning the relationship between variables is similar.

The initial idea of this article was to prove there is an association between the level of education and general happiness. Since the beginning of the article, we did not prejudice the direction of this association. Instead, our alternative hypothesis only stated that these variables are associated.

As we saw in the results section, there is a connection between the variables. This was demonstrated by a test statistic for $\mathrm{H}_{0}$. "The test statistic for $\mathrm{H}_{0}$ : independence summarizes how close the expected frequencies fall to the observed frequencies. Symbolized by $\mathrm{X}^{2}$, it is called the Chisquare statistic" [1].

The chi-square test proved the variables (general education and highest year of school completed recorded in school-college) are associated, which confirms our alternative hypothesis.

By comparing the results gained above in the article, we can say that the test statistic $\left(X^{2}=39.6080\right)$ is higher than the Critical Value (5.99). As chisquared gets bigger, the probability that the null is true (our p-level) gets smaller [3]. Thus, knowing that the larger the $\mathrm{X}^{2}$ value, the more evidence we have against Null Hypothesis $\mathrm{H}_{0}$, makes us conclude we can reject it.

Further, to make sure we can reject $\mathrm{H}_{0}$, we found the $\mathrm{p}$-value based on the degrees of freedom and the test statistic. Since $X^{2}=39.6$, at the row of 2 degrees of freedom in Table 5 , we can see $X^{2}$ is greater than 13.82, meaning that the $p$ value $<0.001$. This is strong evidence we can reject the null hypothesis. Thus, we can confirm our alternative hypothesis which states that there is an association between "general happiness" and the "highest number of school years completed" (recoded to "school-college" variable).

Even by analyzing the GSS variable "Educ" (before recoding it to "school-college"), we would get the same conclusion. In both cases, $\mathrm{X}^{2}>$ Critical Value and $p$-value $<\alpha$, which gives us strong evidence against the null hypothesis.

\section{CONCLUSION}

Overall, we are satisfied we could reject the null hypothesis, even though we have identified some challenges. Our alternative hypothesis declared there is a correlation between the general happiness and the highest number of school years completed. However, it would be interesting to see the direction of that relationship as well.

Although the chi-square test provided us with strong evidence against $\mathrm{H}_{0}$, our research article did not respond to the question of whether the happiness level increases or decreases while completing more school years. Of course, this was not the objective of this article, however, it is an interesting issue to investigate in other articles.

Similarly, the variable of highest school year completed could be mistaken by the highest degree achieved. Although these two variables may sound very similar, they show us different results 
because some of the respondents may have completed more school years, but have not obtained higher degrees. Some of them may have completed more than one major at the same academic level. Others may have completed a major only partially, meaning that their number of school years is higher, but their highest degree remains the same as it was. These two variables are interesting content to be analyzed in future research articles.

Another challenge I had while writing the article was the literature review. Since I consider the topic of this article to be specific and original, I had difficulty finding similar previous research articles. Even some of the authors cited in this article confirmed that there is a lack of studies regarding the topic of happiness and education level. Thus, it was a challenge to compare the findings of this article with the other articles' output.
Finally, I can conclude the article has fulfilled its purpose to prove there is a relationship between the general happiness and the number of school years completed. This was done by using chisquare which provided us with strong evidence against the null hypothesis. Based on that evidence, we have confirmed the alternative hypothesis which stated that the two variables are associated.

\section{DECLARATION OF CONFLICTING INTERESTS}

The author declared no potential conflicts of interest to the research, authorship, and/or publication of this article.

\section{FUNDING}

The author has not received any funding for this article.

\section{REFERENCES}

1. Alan Agrasti, B. F. (2009). Statistical Methods for the Social Science. New Jersey: Pearson Prentice Hall.

2. GSS Data Explorer. (n. d.). About GSS. Retrieved from https://gssdataexplorer.norc.org/pages/show?page=gss\%2Fabout

3. Hanneman, R., Kposowa, A. J., \& Riddle, M. (2013). Basic statistics for social research. San Francisco: Jossey-Bass.

4. Lutz, W. (2015, May). Too Educated to be Happy? An investigation into the relationship between education and subjective well-being. Retrieved from http://pure.iiasa.ac.at/id/eprint/11674/1/IR15-015.pdf

5. Muller, A. (2002). Education, income inequality, and mortality: a multiple regression analysis. $B M J$, 324(7328), 23-23. doi: 10.1136/bmj.324.7328.23

6. Noddings, N. (2003). Happiness and Education. Cambridge: Cambridge University Press.

7. Noval, B. L., \& Garvi, M. G. (2012). Empirical Relationship between Education and Happiness. ShareLife Release, 1, 1-19.

8. Peterson, C., Park, N., \& Seligman, M. E. P. (2005). Orientations to happiness and life satisfaction: the full life versus the empty life. Journal of Happiness Studies, 6(1), 25-41. doi: 10.1007/s10902-0041278-z

9. Putnam, R. (2000). Bowling Alone: The Collapse and Revival of American Community. New York: Simon \& Schuster.

10. Striessnig, E. (2015). Too Educated to be Happy? An Investigation into the Relationship between Education and Subjective Well-being. Retrieved from http://pure.iiasa.ac.at/id/eprint/11674/1/IR15-015.pdf

11. Wilson, L. (2009, May 2). Statistical Correlation. Retrieved from https://explorable.com/statisticalcorrelation 